\title{
International Journal of Biological Macromolecules
}

\section{$\beta$-Amyloid peptide interactions with biomimetic membranes: A multiparametric characterization}

\author{
Willy Smeralda a, Marc Since ${ }^{\mathrm{a}, *}$, Julien Cardin ${ }^{\mathrm{b}}$, Sophie Corvaisier ${ }^{\mathrm{a}}$, Sophie Lecomte ${ }^{\mathrm{c}}$, \\ Christophe Cullin ${ }^{\mathrm{c}}$, Aurélie Malzert-Fréon ${ }^{\mathrm{a}}$ \\ a Normandie Univ, UNICAEN, CERMN, 14000 Caen, France \\ b NIMPH Team, CIMAP CNRS UMR 6252, EnsiCaen-UNICAEN-CEA, 14050 Caen, France \\ c CBMN, CNRS UMR 5248, Univ. Bordeaux, 33600 Pessac, France
}

Keywords:

Alzheimer's disease

Liposomes

B-Amyloid

Membranes

\begin{abstract}
A B S T R A C T
Alzheimer's disease is the most common form of senile dementia in the world, and amyloid $\beta$ peptide $1-42\left(A \beta_{1}\right.$ ${ }_{42}$ ) is one of its two principal biological hallmarks. While interactome concept was getting forward the scientific community, we proposed that the study of the molecular interactions of amyloid $\beta$ peptide with the biological membranes will allow to highlight underlying mechanisms responsive of AD. We have developed two simple liposomal formulations (phosphatidylcholine, cholesterol, phosphatidylglycerol) mimicking neuronal cell membrane (composition, charge, curvature radius). Interactions with $A \beta_{1-42}$ and mutant oG37C, a stable oligomeric form of the peptide, were characterized according to a simple multiparametric procedure based on ThT fluorescence, liposome leakage assay, ATR-FTIR spectroscopy. Kinetic aggregation, membrane damage and peptide conformation provided our first methodologic bases to develop an original model to describe interactions of $A B$ peptide and lipids.
\end{abstract}

\section{Introduction}

Amyloids refer to a group of soluble proteins or peptides that have the ability to aggregate as insoluble deposits. The presence of such deposits within biological tissues characterizes known diseases as amyloidosis. Many amyloid proteins have been identified in humans, some of them are associated with neurodegenerative diseases like Alzheimer's disease (AD) [1,2]. AD is the most widespread form of senile dementia worldwide and represents the leading socioeconomic problem in healthcare. The onset and the progression of this neurodegenerative disease are associated with the aggregation of the amyloid- $\beta$ peptide $(A \beta)[3]$.

The amyloid aggregation process consists in the fibrillation of the $A B$ peptide from monomeric species to fibers, the major components of the amyloid plaques. The intermediary states, corresponding to oligomeric species, are considered to be responsible for the neuron toxicity [4,5]. The fibrillation pathway can be divided into 3 phases: $i$. the nucleation where the nuclei are formed, $i$. the elongation corresponding to the assembly of the nuclei into protofibrils passing by intermediary species

Corresponding author.

E-mail addresses: marc.since@unicaen.fr (M. Since), juliencardin@ensicaen.fr (J. Cardin), sophie.corvaisier@unicaen.fr (S. Corvaisier), sophie.lecomte@u-bordeaux.fr (S. Lecomte), christophe.cullin@u-bordeaux.fr (C. Cullin),

aurelie.malzert-freon@unicaen.fr (A. Malzert-Fréon). such as the oligomeric state, and then iii. the saturation phase corresponding to the maturation of the fibers and to an equilibrium phase. The whole process is characterized by an increase of the $\beta$-sheet secondary structure. Indeed, amyloids are ordered cross $\beta$-sheet protein aggregates consisting of fibers arranged in $\beta$-sheets perpendicular to the axis of the fiber [6,7]. The aggregation process involves both homotypic $(A \beta-A \beta)$ and heterotypic $(A \beta$ with interacting partners in its environment) interactions. Factors, influencing this process are numerous, and among them many physicochemical parameters such as temperature, $\mathrm{pH}$ or concentration are widespread recognized. These factors can also be molecular actors present in the peptide environment such as metal ions and membrane lipids [8].

Lipids like ganglioside GM1, cholesterol and sphingomyelin have been largely described as being able to interact with $A B$ fibrillation process [9-14]. However, the peptide would also tend to interact with other lipids such as phosphatidylserine or phosphatidylethanolamine [15-17]. In order to study these interactions in vitro, many membrane models have been used such as monolayers, bilayers, micelles or liposomes $[15,16,18,19]$. All these studies revealed numerous effects of the presence of membrane lipids, albeit sometimes with contradictory results, depending on the peptide source, the operating conditions or the membrane model.

The main objective of the present article was to set up a multiparametric assay allowing the characterization and modelisation of $A \beta_{1-42}$ peptide interactions with a simple biomimetic membrane 
model. Taking advantage of our previous work using liposomes [20], large unilamellar vesicles (LUVs) were used as membrane model. Using a simplified composition based on phosphatidylcholine (SPC), cholesterol (Chol) and phosphatidylglycerol (DOPG), a lipid environment mimicking neuronal membranes, could be recreated to enable physico-chemical studies. Interactions between $A \beta$-peptide or the stable oligomeric peptide variant, oG37C and membranes have been established from various spectroscopic studies. Results were expressed in terms of fibrillation kinetic variations, membrane damage and peptide conformation.

\section{Materials and methods}

\subsection{Materials}

Soybean phosphatidylcholine (SPC), 1,2-dioleoyl-sn-glycero-3phosphoglycerol, sodium salt (DOPG) were gifts from Lipoid $\mathrm{GmbH}$ (Ludwigshafen, Germany). 3-(trimethylsilyl) propionic-2,2,3,3- $\mathrm{d}_{4}$ acid (TMSP), carboxyfluorescein (CF), cholesterol, dimethyl sulfoxide (DMSO), potassium chloride, potassium phosphate, Sepharose ${ }^{\circledR} \mathrm{CL}-$ 4B, sodium chloride, sodium phosphate, thioflavin T, Triton X-100 were purchased from Sigma-Aldrich (Saint-Quentin Fallavier, France). Ammonium hydroxide was obtained from VWR (Randor, Pennsylvanie, USA), dithiothreitol from Thermo Fisher Scientific (Waltham, Massachusetts, USA). Recombinant $A \beta_{1-42}$ was purchased from rPeptide (Watkinsville, GA 30677, USA).

\subsection{Liposomes}

\subsubsection{Formulation of liposomes}

Liposomes mixtures of SPC:chol:DOPG in a molar ratio of $6: 2: 2$ $\left(\mathrm{PCG}_{622}\right)$ or 2:2:6 ( $\left.\mathrm{PCG}_{226}\right)$ were used. Liposomes were formulated according to the adapted method of the thin lipid film hydration [21]. Lipid solutions in chloroform/methanol (4:1) were evaporated under nitrogen flow, and left under vacuum for 3-4 h to form a lipid film. This thin lipid film was then hydrated in PBS buffer $(137 \mathrm{mM} \mathrm{NaCl}$, $2.7 \mathrm{mM} \mathrm{KCl}, 10 \mathrm{mM} \mathrm{Na}_{2} \mathrm{HPO}_{4}$ and $2 \mathrm{mM} \mathrm{KH}_{2} \mathrm{PO}_{4}$ ) and vortexed. Rehydrated lipid suspensions were subjected to $1 \mathrm{~h}$ of gentle agitation in order to have maximum homogenization. Free-thaw cycles were carried out with liquid nitrogen and a $40{ }^{\circ} \mathrm{C}$ water bath. The yielded multilamellar vesicles (MLVs) were then extruded 13 times with a mini-extruder (Avanti Polar Lipids, Inc., Alabaster, Alabama, USA) through polycarbonate membranes with a pore diameter of $100 \mathrm{~nm}$ (Avanti Polar Lipids, Inc., Ref: 800309) to form LUVs.

\subsubsection{Characterization of liposomes by dynamic light scattering}

The average hydrodynamic diameter associated with the polydispersity index (PdI) of the formulated LUVs were measured by dynamic light scattering (DLS) using a NanoZS ${ }$ apparatus (Malvern Instruments SA, Worcestershire, UK) equipped with a $633 \mathrm{~nm}$ laser at a fixed scattering angle of $173^{\circ}$. The zeta potential was calculated from the electrophoretic mobility using the Smoluchowski equation, also using a NanoZS $₫$ apparatus. The measurements were performed in triplicate at $25{ }^{\circ} \mathrm{C}$ after a 1:100 (v/v) dilution in the buffer.

\subsubsection{Lipid quantification by NMR spectroscopy}

The lipid concentration of the formulated LUVs was quantified by ${ }^{1} \mathrm{H}$ NMR spectroscopy [22]. ${ }^{1} \mathrm{H}$ NMR measurements were performed at ambient temperature for SPC, and DOPG-based LUVs, or at $50{ }^{\circ} \mathrm{C}$ for $\mathrm{PCG}_{622}$ and PCG $_{226}$ LUVs on a Bruker Avance III spectrometer (Bruker, Billerica, Massachusetts, USA) equipped with a $5 \mathrm{~mm}$ probehead operating at 400 $\mathrm{MHz}$. The instrument's standard settings ( $90^{\circ}$ pulse angle, $2.72 \mathrm{~s}$ acquisition time, $3 \mathrm{~s}$ relaxation delay, $15 \mathrm{ppm}$ spectral width) were used. Locking and shimming was performed on the signal of the exchangeable deuterium atoms of the $\mathrm{D}_{2} \mathrm{O} / \mathrm{CD}_{3} \mathrm{OD}$ mixtures. 64 scans were performed leading to a total acquisition time of 6 min $20 \mathrm{~s}$. Data processing was performed with Topspin 3.5 After zerofilling to $64 \mathrm{k}$ data points, apodization (exponential and Gaussian functions, $1 \mathrm{~Hz}$ ), Fourier transformation, phase- and baseline correction, the peak areas were determined by integration. TMSP was used as an internal standard $(\delta=0$ $\mathrm{ppm})$. For samples with increased amounts of water, presaturation of the water peak ( $\delta=4.79 \mathrm{ppm}$ ) was used to ensure that the dynamic range of the instrument was not exceeded during the measurement. To prevent overlapping signals above $\delta=0.8 \mathrm{ppm}$ phospholipid quantification was made using the signal around $\delta=0.67 \mathrm{ppm}$ originating from the C18 methyl group of cholesterol.

\subsubsection{Liposomes leakage assay (LLA)}

Carboxyfluorescein (CF)-loaded LUVs were prepared by the thin lipid film hydration as described in Section 2.2.1. The hydration step was carried out with a $70 \mathrm{mM}$ CF solution prepared in PBS buffer. The obtained LUVs were separated from unincorporated CF by passage through a Sepharose ${ }^{\circledR}$ CL-4B loaded (Sigma-Aldrich) column, using PBS buffer as eluent. The LUVs were characterized by DLS and the lipids were quantified by NMR spectroscopy as described in Sections 2.2.2, and 2.2.3, respectively. The dequenching of the CF fluorescence was measured using a Synergy 2 microplate reader (Biotek, Colmar, France) equipped with the appropriate filters ( $\lambda$ ex $=485 / 20 \mathrm{~nm}$ and $\lambda_{\mathrm{em}}=528 / 20 \mathrm{~nm}$ ). CF release assay was performed in a final volume of $100 \mu \mathrm{L}$, using $10 \mu \mathrm{M}$ of LUVs. The fluorescence was recorded immediately (F0) and for $4 \mathrm{~h}$ at $25^{\circ} \mathrm{C}$. It was compared with that measured at the end of the experiment after addition of $2 \mu \mathrm{L}$ of $20 \%$ Triton X-100 solution to achieve complete liposome leakage (Fmax). To validate the Liposome Leakage Assay results, the sensibility rate $\mathrm{R}=$ Fmax/F0 was calculated, and it had to be greater than 6 to perform studies. Then, the percentage of $\mathrm{CF}$ release was calculated according to the following equation [23]:

$\%_{\mathrm{CF}}$ leakage $(\mathrm{t})=\frac{\mathrm{Ft}-\mathrm{F} 0}{\mathrm{Fmax}-\mathrm{F} 0} \times 100$

where Ft was the fluorescence intensity at time t, F0 the initial fluorescence intensity, and Fmax the final fluorescence intensity after addition of Triton X-100.

The data of LLA were plotted with GraphPad $®$ Prism statistical software (version 6.01, GraphPad $®$ Software, La Jolla, CA, USA). Comparison at references values (oG37c alone) were performed with MannWhitney test. Differences were considered significant when the associated $\mathrm{p}$ value was below 0.05 .

\subsection{Amyloid- $\beta$ peptide}

\subsection{1. $A \beta$ treatment}

The $A \beta_{1-42}$ from rPeptide lyophilized powder was solubilized in $1 \%$ $\mathrm{NH}_{4} \mathrm{OH}$, at a concentration of $1 \mathrm{mg} / \mathrm{mL}$. After $3 \mathrm{~min}$ of sonication, resuspension was achieved using PBS buffer at $\mathrm{pH} 6.3$ to reach a final $\mathrm{pH}$ around 7.4.

\subsubsection{Production and purification of oG37C}

oG37C variant was produced and purified with minor modifications of the protocol previously described [24]. Briefly, after transformation in the bacterial strain 969 (Bl21de3pLysS) with the plasmid pET Sac Abeta, one clone was grown on $10 \mathrm{~mL}$ LB medium preculture that contained $1 \%$ dextrose, $100 \mathrm{mg} / \mathrm{L}$ ampicillin, and $25 \mathrm{mg} / \mathrm{L}$ chloramphenicol. This oneday preculture was added to $990 \mathrm{~mL}$ of ZYM medium (1\% Tryptone, $0.5 \%$ yeast extract, $25 \mathrm{mM} \mathrm{Na}_{2} \mathrm{HPO}_{4}, 25 \mathrm{mM} \mathrm{KH}_{2} \mathrm{PO}_{4}, 50 \mathrm{mM} \mathrm{NH}_{4} \mathrm{Cl}, 5 \mathrm{mM}$ $\mathrm{Na}_{2} \mathrm{SO}_{4}, 2 \mathrm{mM} \mathrm{MgSO}$ ) containing $100 \mathrm{mg} / \mathrm{mL}$ ampicillin and 25 $\mathrm{mg} / \mathrm{mL}$ chloramphenicol and incubated overnight at $37^{\circ} \mathrm{C}$. Cell pellet $(1 \mathrm{~g} / 2.5 \mathrm{~mL}$ of TE buffer) were subjected to 3 cycles of sonication (respectively 5,4 and 2 sonication of $1 \mathrm{~min}$ on ice, output $40 \%$ ), and then centrifuged for $15 \mathrm{~min}$ at $30,000 \mathrm{~g}$ at $4{ }^{\circ} \mathrm{C}$ after each cycle. The pelleted inclusion bodies were solubilized at $1.25 \mathrm{mg}$ per $10 \mathrm{~mL}$ of TE-urea buffer 
(8 M urea, $50 \mathrm{mM}$ Tris, $1 \mathrm{mM}$ EDTA pH 8). After overnight at $4{ }^{\circ} \mathrm{C}$ with gentle agitation, the soluble inclusion bodies were centrifuged for $30 \mathrm{~min}$ at $30,000 \mathrm{~g}$ at $4{ }^{\circ} \mathrm{C}$. The supernatant was passed through a 30 $\mathrm{kD}$ filtration unit for $2 \mathrm{~h}$ at $4000 \mathrm{~g}$ at $4{ }^{\circ} \mathrm{C}$ and concentrated on a $5 \mathrm{kD}$ membrane at $4000 \mathrm{~g}$ at $4{ }^{\circ} \mathrm{C}$. Monomeric and oligomeric species of oG37C were separated by size-exclusion chromatography on a Superdex-75 10/300 GL Column equilibrated in phosphate-buffered saline (PBS, $137 \mathrm{mM} \mathrm{NaCl}, 2.7 \mathrm{mM} \mathrm{KCl}, 10 \mathrm{mM} \mathrm{Na}_{2} \mathrm{HPO}_{4}, 1.76 \mathrm{mM}$ $\mathrm{KH}_{2} \mathrm{PO}_{4}, \mathrm{pH} 7.4$ ) at $4{ }^{\circ} \mathrm{C}$. The fractions were pooled separately, and aliquots were quantified with a Bradford assay, frozen in liquid nitrogen, and conserved at $-80{ }^{\circ} \mathrm{C}$ until use.

\subsubsection{Aggregation kinetic assay (ThT, Thioflavin T fluorescence)}

Concentrated solution of $A \beta_{1-42}$ peptide was diluted in PBS while oG37C was diluted in PBS with DTT. $10 \mu \mathrm{M}$ of A $\beta$ were incubated in 96-well dark plates in presence of absence of liposomes with $20 \mu \mathrm{M}$ of ThT at $25{ }^{\circ} \mathrm{C}$. Fluorescence measurements $(\lambda$ exc $=440 \mathrm{~nm}$ and $\lambda \mathrm{em}$ $=484 \mathrm{~nm}$ ) were made with an Infinite M200 microplate reader (Tecan, Männedorf, Switzerland). Data were collected as the average of 25 flashes each $10 \mathrm{~min}$ with $20 \mathrm{~s}$ of $1 \mathrm{~mm}$ orbital agitation before each run.

\subsubsection{Attenuated Total Reflectance-Fourier Transform InfraRed spectros- copy (ATR-FTIR)}

Samples were incubated overnight at $25^{\circ} \mathrm{C}$ before FTIR experiments. $3 \mu \mathrm{L}$ of each sample was loaded on a germanium crystal and dried with a stream of dry nitrogen. ATR-FTIR spectra were recorded on a Nicolet iS50 FTIR spectrometer (Thermo Fisher Scientific, San Jose, CA, USA) equipped with DLaTG (Deuterated Lanthanum $\alpha$-alanine-doped TriGlycine sulfate) and MCT (Mercury Cadmium Telluride) detectors with a spectral resolution of $2 \mathrm{~cm}^{-1}$.

128 interferograms were recorded during a 2 min acquisition process. All FTIR experiments were done in a thermostatically controlled room at $25^{\circ} \mathrm{C}$ (Fig. S2).

\section{Results}

\subsection{Liposomal model formulation}

In regard of the complex composition of biological cellular membranes, model monolayers and bilayers are widely used as biomimetic cellular membranes to study the interactions between $A \beta$ peptide and the neuronal membranes in vitro. Among them, large unilamellar vesicles (LUVs) are particularly interesting because, they can be easily and reproducibly produced by extrusion techniques [25]. With a $100-500$ $\mathrm{nm}$ diameter range, that may be regulated by the pore sizes of polycarbonate membranes, LUVs appear more stable in time than small unilamellar vesicles (SUVs). SUVs show highly curved nature of their
Table 1

Physico-chemical properties of the formulated LUVs expressed in terms of mean hydrodynamic diameter $(\varnothing)$, polydispersity index (PdI), zeta potential value, concentration of lipids, determined immediately after formulation $(\mathrm{n}=3)$.

\begin{tabular}{lllll}
\hline & $\varnothing(\mathrm{nm})$ & PdI & $\zeta$ pot $(\mathrm{mV})$ & Lipids concentration $(\mathrm{mM})$ \\
\hline $\mathrm{PCG}_{622}$ & $113.5 \pm 1.7$ & $0.068 \pm 0.001$ & $-22.6 \pm 2.3$ & $20.0 \pm 5.0$ \\
$\mathrm{PCG}_{226}$ & $120.4 \pm 0.8$ & $0.032 \pm 0.020$ & $-38.9 \pm 1.4$ & $20.0 \pm 5.0$ \\
\hline
\end{tabular}

membrane, resulting in more packing defects than LUVs. Moreover, LUVs offer a similar curvature to the cell membranes [26], and this parameter appeared to be crucial for $A \beta$-lipids interactions $[27,28]$. Several studies, based on artificial membrane models to study $A \beta$ interactions with neuronal membranes, used compositions containing phosphatidylcholine, cholesterol, sphingomyelin and ganglioside GM1 $[11,13,18,19,29]$. As the design of a model easy to produce, easy to use, stable and not expensive was essential, phosphatidylcholine was replaced by soybean phosphatidylcholine (SPC), and phosphatidylglycerol (PG) was preferred to GM1. PG can be viewed as a simplistic GM1 model, and by the use of such a negatively charged phospholipid, that presents surface hydroxyl groups, it is possible to highlight electrostatic interactions and the ability of the membrane to form $\mathrm{H}$-bonds with interacting peptide moieties $[18,30]$. As lipid membranes rigidity or fluidity can also influence protein aggregation, and considering also that cholesterol, an essential component of neuronal membrane (20-30\%) [18,31], could play a pivotal role in the $A \beta$ peptide/membrane interactions [14], it appeared essential to imply cholesterol in our membrane models. In consequence, the formulated LUVs were composed of soybean phosphatidylcholine (SPC), cholesterol and 1,2-dioleoyl-sn-glycero-3-phosphoglycerol (DOPG) (Fig. 1).

In coherence with the composition of the neuronal membranes [18], liposomes were formulated using mixtures of SPC:cholesterol:DOPG in a molar ratio of 6:2:2 ( PCG $\left._{622}\right)$. Other liposomes with a SPC:cholesterol:DOPG molar ratio of 2:2:6 ( PCG $_{226}$ ) were also used to highlight the possible impact of the overall ionic charge of lipids on the aggregation process. Negative membrane charge could be of peculiar importance to favor membrane disruption by amyloid peptide [30].

\subsection{Liposomes characterization}

After formulation according to Bangham method [21], the lipid concentration of the colloidal suspension was checked using a ${ }^{1} \mathrm{H}$ NMR quantification as developed in a previous work by our team [20]. The granulometric properties of the liposomes were also determined (Table 1). The average diameter of the liposomes was found to be about one hundred nanometers which was coherent with the expected size for the large unilamellar vesicles formulated by extrusion in our conditions. The polydispersity indices being less than 0.1 , showed the

A.

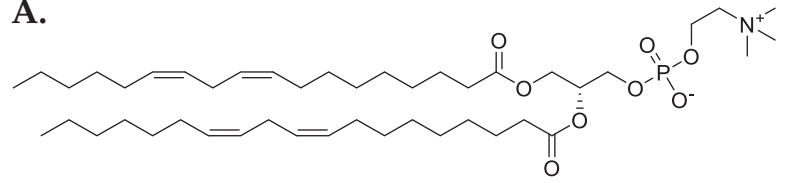<smiles>[R][P]</smiles>

C.

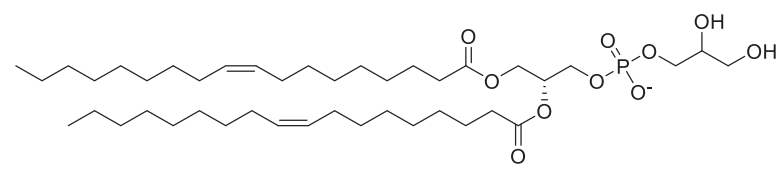

Fig. 1. Molecular structures of A. soybean phosphatidylcholine (SPC) major component; B. cholesterol; C. 1,2-dioleoyl-sn-glycero-3-phosphoglycerol (DOPG). 
presence of monomodal liposome populations for both LUVs. The zeta potential values, indicative of the surface charge of the LUVs, were negative as expected for PG-based LUVs, since PG is negatively ionized and its proportion in the LUVs was significant.

\subsection{ThT monitoring of $A \beta$ peptide aggregation in absence and presence of liposomes}

Thioflavin $\mathrm{T}$ is a well-known dye fluorescing when the $\beta$-sheet secondary structure of a peptide or a protein increase [32]. This property allowed to follow the increase of the $\beta$-sheet content during the $A \beta$ peptide aggregation and thus to follow its kinetics. The aggregation kinetic of $A \beta_{1-42}$ alone showed the classical phases of amyloid aggregation with a lag phase of approximately $60 \mathrm{~min}$, then an elongation phase of approximately $240 \mathrm{~min}$ to reach the equilibrium phase (Fig. 2. A).

In the presence of PCG $_{622}$-based LUVs, results did not show any major quantitative difference at the kinetic plateau. The normalized representation (Fig. S1. A.) allowed to isolate kinetic data [33]. They could be compared in presence of three concentrations of $P C_{622-}$ based LUVs. The presence of LUVs appeared to affect $A \beta$ aggregation. At 10 and $100 \mu \mathrm{M}$, a concentration-dependent delay in the fibrillation process was observed.

Moreover, at this concentration range, the slope of the elongation phase was slightly decreased with lipid concentration. Plateau phases were reached after 350 and 400 min for 10 and $100 \mu \mathrm{M}$ LUVs, respectively. Interestingly, when the lipid concentration increased to $1 \mathrm{mM}$, a decrease in the delay of the fibrillation process was observed, and the slope of the elongation phase came back to that observed with $A \beta_{1-42}$ alone. Considering these results, it appeared that the inhibitory effect of the PCG $_{622}$ liposomes is essentially a kinetic effect leading to an increase of the lag phase and a decrease of the rate of elongation. This could indicate that the main interactions between the peptide and the membranes were at the level of the species present at the nucleation phase, or during oligomerization. Obviously, it could be interesting to be able to precisely discriminate all the present various species, and to quantify their degree of attachment to membranes all along the aggregation kinetics. For example, Bhowmik et al. [34] developed assays, either based on fluorescence correlation spectroscopy or on a dialysis step followed by conventional fluorescence spectroscopy, to measure the difference in membrane affinity between the monomers and small oligomers of $A \beta$ in the early steps of aggregation. They showed that under identical concentrations, small oligomers attach to the model membranes (SUVs) at least an order of magnitude more strongly than do the monomers. However, according to the experimental conditions, as the peptide/lipids ratio, oligomers structures may be heterogeneous [35], and it discriminate all their different structures, and also quantify simultaneously forming fibrils.

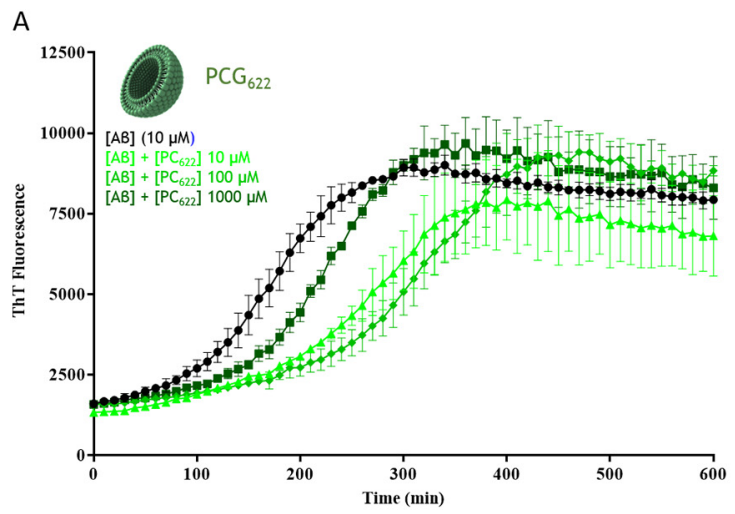

It was recently reported that each LUVs component possesses its own effect on $A \beta$ peptide aggregation kinetics, ranging from enhancement to inhibition, while lipid mixtures tend to average out the effects of individual components [36]. An extension to this finding should be that the amyloid $\beta$ peptide/PCG ${ }_{622}$ molar ratio would impact aggregation kinetics in a similar way. Another explanation to the observed effect should be the existence of a secondary nucleation pathway. Indeed, an aggregation study of A $\beta$ on zwitterionic DOPC-based LUVs by FRET analysis reported that the liposomes were able to catalyze fibril formation via secondary nucleation mechanisms involving aggregate fragmentation [37]. As in this study, secondary pathways induced by oligomeric forms of $A \beta$ on the membrane surface could appear beyond a critical concentration of $\mathrm{PCG}_{622}$-based LUVs.

As $A \beta$ is negatively charged [29], the impact of its electronegative interactions with membranes was deeper explored by increasing the proportion of phosphatidylglycerol, and therefore the proportion of negative charges, in the composition of liposomes. Thus, in the presence of $\mathrm{PCG}_{226}$-based LUVs at $10 \mu \mathrm{M}$, no difference with $A \beta_{1-42}$ own aggregation was detected from a quantitative and a kinetic point of view (Figs. 2. B, S1). At $100 \mu \mathrm{M}$ and $1 \mathrm{mM}$ of lipids, a similar kinetic delay has been observed, with extension of the nucleation phase, and mostly of the elongation phase. The equilibrium plateau was reached after 400 min vs 300 min when $A \beta_{1-42}$ was incubated alone. Moreover, at $100 \mu \mathrm{M}$ of PCG $_{226}$-based LUVs, the reached fluorescence plateau observed was lower than in other cases. This could indicate the formation of different $A \beta$ forms with less ThT binding abilities or a quantitative difference in terms of length or amount of fibers formed.

The mechanism of ThT binding has been described by Biancalana and Koide as a channel model of binding. ThT was proposed to bind along surface side-chain grooves running parallel to the long axis of the $\beta$-sheet [32]. It was therefore possible that structural changes occur while limiting the binding of ThT which would prevent the observation of differences in simple fluorescence monitoring. We therefore decided to study the secondary structure of the peptide with or without liposomes using the ATR-FTIR spectroscopic technique by incubating overnight, under gentle agitation, at $25^{\circ} \mathrm{C}, A \beta_{1-42}(50 \mu \mathrm{M})$ alone, or in presence of liposomes $(100 \mu \mathrm{M})$. Concentrations were chosen in order to measure significant ATR-FTIR absorbance of peptide with the same concentration ratio used in the ThT assays ([lipids] / [peptide] $=2$ ).

ATR-FTIR spectroscopy was used to analyze the secondary structure of peptides and proteins, in particular by analyzing the amide band I (1700-1600 $\mathrm{cm}^{-1}$ ) corresponding mainly to the $\mathrm{C}=0$ vibration mode of the peptide bond [38]. The position of the amide I band and its profile on the spectrum allowed to identify the main secondary structural elements present in the sample. It should be noticed that the recorded spectra corresponded to the signature of all proteins present in the bulk (free or interacting with the liposomes).

B

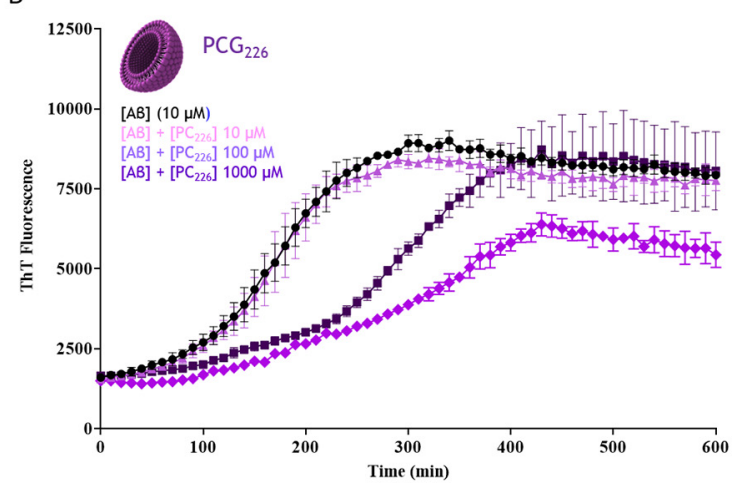

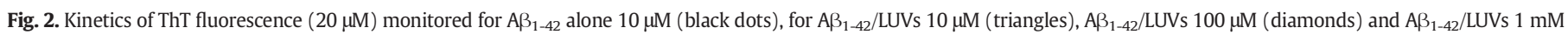
(squares) A. with $\mathrm{PC}_{622}$-based LUVs, or $\mathrm{B}$. with $\mathrm{PC}_{226}$-based LUVs. The error bars represent the standard deviation of 3 samples. 
Fig. 3 shows the ATR-FTIR spectra of $A \beta_{1-42}$ peptide alone, with $\mathrm{PC}_{622}$ or $\mathrm{PC}_{226}$ formulations in the range of the amide I band. The most intense band at $1629 \mathrm{~cm}^{-1}$ was characteristic of parallel $\beta$-sheet conformation, as expected with the formation of amyloid fibers [39]. A broad band at higher wavenumbers, centered at $1665 \mathrm{~cm}^{-1}$, revealed the presence of other secondary structural elements mainly $\beta$-turns but also few contributions of random coil and $\alpha$-helices $[40,41]$. Experiments conducted with liposomes were further analyzed by subtracting the absorbance signal from blank containing the same concentration of lipids. It can be noticed that in the amide I band, the lipids absorbance was very lower than that obtained for the peptide (Fig. S2. C).

The amide band I profile measured for $A \beta_{1-42}$ peptide in presence of $P_{6 G_{622}}$-based liposomes was very similar to the one obtained for the peptide alone (Fig. 3 green curve). However, the proportion of the amide group involved in parallel $\beta$-sheet structures was decreased in presence of liposomes in favor to other structural elements as $\beta$-turns or $\alpha$-helices. The presence of lipidic formulation seemed to delay the $A \beta_{1-42}$ fibrillar process by stabilization of intermediary species in agreement with our ThT results. Interestingly, in presence of PCG $_{226}$, the similar decrease of the parallel $\beta$-sheet conformation was observed in favor of $\beta$-turns or $\alpha$-helices, and a new band was observed at higher wavenumber $\left(1693 \mathrm{~cm}^{-1}\right.$ ) (Fig. 3, pink curve, thin arrow). In antiparallel $\beta$ sheet structures, the amide I region displayed two typical components. The major component had an average wavenumber located at 1630 $\mathrm{cm}^{-1}$, whereas the minor component, approx. 5-fold weaker than the major one, was characterized by a wavenumber at around $1695 \mathrm{~cm}^{-1}$. The appearance of this last band allowed to identify that some $A \beta_{1-42}$ peptides were organized in anti-parallel $\beta$-sheet conformation. Such antiparallell $\beta$-sheet conformations were previously described for membrane-interacting $A \beta$ oligomers [42]. However due to the overlap of the band at low wavenumber $\left(1630 \mathrm{~cm}^{-1}\right)$ with the signature of parallel $\beta$-sheets, it was not possible to determine the relative percentage of each individual parallel and anti-parallel $\beta$-sheets structure. According to Sarroukh et al., the presence of such an anti-parallel $\beta$-sheet conformation is the fingerprint of earliest intermediary species, as oligomers [38]. Others consider also it as the hallmark of the offpathway releasing membrano-toxic oligomers [30]. Recently, an original Surface Enhanced Raman Spectroscopy study showed A $\beta$ peptide could adopt an antiparallel $\beta$-sheet/ $\beta$-turn conformations similar to porins structure in the membrane [42].

Many studies have reported the study of interactions of $A \beta$ with lipids $[8,9,11,13,14,43,44]$ where $A \beta$ interactions with the anionic phospholipids-based liposomes are often demonstrated to be limited to the lipid surface at neutral $\mathrm{pH}$, eventually accompanied by partial

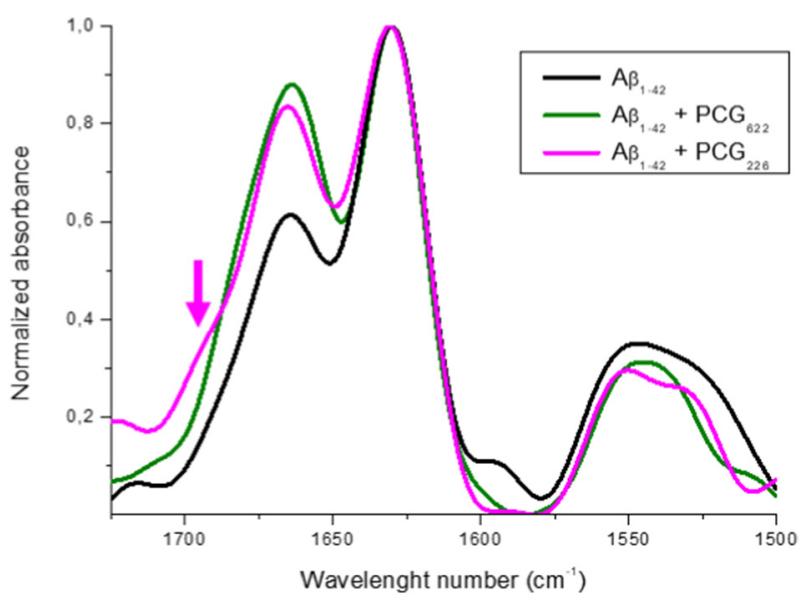

Fig. 3. ATR-FTIR spectra of amide band I and II absorbance of $A \beta_{1-42}$ peptide alone, with $\mathrm{PC}_{622}$ or $\mathrm{PC}_{226}$ formulations normalized to the $\beta$-sheet conformations band (1629 $\left.\mathrm{cm}^{-1}\right)$. The pink arrow shows the anti-parallel $\beta$-sheet conformation at $1693 \mathrm{~cm}^{-1}$ of $A \beta_{1-42}$ with $\mathrm{PCG}_{226}$-based LUVs. insertion of $A \beta$ into the membrane. In coherence with other works made on different liposomes [45], our results show that the surface characteristics of the membranes, and in particular the nature of the phospholipids head groups, modulate $A \beta$ aggregation, and in extenso behave as a specific factor for $A \beta$ conformations during aggregation.

In recent years, studies relative to the $A \beta$ peptide aggregation have focused on the existence of intermediate oligomeric species [39,46-53]. Indeed, a stable and homogeneous solution of $A \beta$ in oligomeric form is really difficult to obtain [54-56]. In order to work with a solution containing exclusively oligomers, a stable mutant model synthesized by Vignaud et al. [24], was used. This mutant, named oG37C, obtained after mutagenesis of $A \beta$, has been identified as the most toxic stable oligomeric mutant among 6000 clones. From tipenhanced Raman spectroscopy analysis [57], mass spectrometry [47] and high speed atomic force microscopy [29], it was established, that the size and the height distributions of oG37C are homogeneous. oG37C presents an average diameter around $20 \mathrm{~nm}$ and a height around $10 \mathrm{~nm}$, which corresponds to 7 to 15 monomers [29,47].

\section{4. oG37C aggregation in absence and presence of liposomes}

Since its isolation, many in vitro works described oG37C aggregation process with a particular emphasis on its membrane damage effect $[29,30,47,57,58]$. Interactions between oG37C and liposomes have been established by Henry et al. to be favored in the presence of PG head groups. From studies performed on simple pure DOPC or DOPGbased LUVs models, they showed this peptide interacts with membranes via hydrogen bonding rather than by electrostatic forces [30]. Using ThT assay, liposome leakage assay (LLA), Transmission Electronic Microscopy (TEM) experiments and Plasmon-Waveguide Resonance (PWR) spectroscopy, they showed that oG37C is able to destabilize liposomes made of DOPG. They also showed that GM1 was necessary to promote its interactions with membranes. A drastic detergent effect was observed when GM1 was combined with cholesterol [29]. However, to date, no study has been reported on liposomes based on $\mathrm{PCG}_{622}$ or $\mathrm{PCG}_{226}$.

Using the PCG ${ }_{622}$-based LUVs, no significant leakage was observed upon exposure to oG37C whatever the lipid:peptide ratio (Fig. 4). In the case of $\mathrm{PCG}_{226}$-based LUVs, the most important leakage was detected for the (1:1) lipid:peptide molar ratio (11.6\%). This ratio may seem high in comparison with in vivo $\mathrm{A} \beta$ concentrations $(<\mu \mathrm{M})[59]$. However, it can be noted that when the peptide adsorbs on the cellular membrane, it may reach very high localized concentrations within membranes $(>\mu \mathrm{M})$ whereas being present in the nM range in the bulk

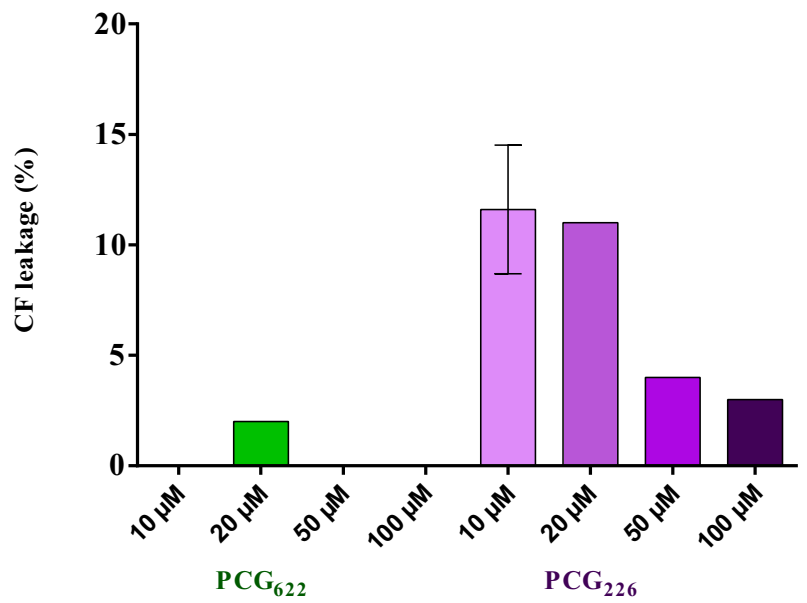

Fig. 4. Carboxyfluorescein leakage from $\mathrm{PCG}_{622}$-based $L U V$ s and $\mathrm{PCG}_{226}$-based LUVs used either at $10,20,50,100 \mu \mathrm{M}$ in presence of oG37C $(10 \mu \mathrm{M})$ after $2 \mathrm{~h}$ of incubation at 25 ${ }^{\circ} \mathrm{C}$. The leakage values were calculated from average values of triplicates, except for $\mathrm{PC}_{226}$ at $10 \mu \mathrm{M}$ that is an average value $\pm \mathrm{SD}$ of three independent experiments. 
[60,61]. At the same (1:1) lipid:peptide ratio, Henry et al. reported approximatively $45 \%$ of leakage using DOPG-based LUVs vs less than 3\% using DOPC-based LUVs [30]. The lower leakage proportion observed here could be due to the presence of cholesterol, which is known to stiffen the membranes above the phase transition temperature (Tm) of phospholipids [62]. Our results showed that the PG proportion plays an important role towards the oG37C toxicity on LUVs models, and the lipid:peptide molar ratio too. Effects being more objectified at the (1:1) PCG $_{226}$ :oG37C molar ratio, we therefore decided to further investigate the effects of liposome/peptide interactions at the kinetic and conformational point of view in these conditions.

Using the ThT fluorescence assay, in $800 \mathrm{~min}$ of incubation time, oG37C showed a characteristic linear aggregation kinetics (Fig. 5). This result was coherent with that previously described by Bobo et al. [47]. In their study, they showed that in the presence of the small redox molecule dithiothreitol (DTT), the appearance of a sigmoid curve characteristic of amyloid aggregation was observed after a long incubation time (960 min) [47].

In the present study, considering the lower concentration of oG37C $(10 \mu \mathrm{M} v s 30 \mu \mathrm{M})$ and the lower temperature $\left(25^{\circ} \mathrm{C} v s 30^{\circ} \mathrm{C}\right)$, it was therefore expected slower kinetics, that allowing us to focus on the early interactions between oligomer species and lipids. The incubation of oG37C in the absence and in the presence of the two liposomal models didn't show a significant difference in the fluorescence signals of ThT. However, despite the background noise, a slight decrease of the signal in the presence of PCG226-based LUVs was observed.

The secondary structure analysis of the peptide using the ATR-FTIR spectroscopy was performed by incubating overnight, under gentle agitation, at $25^{\circ} \mathrm{C}, \mathrm{oG} 37 \mathrm{C}(50 \mu \mathrm{M})$ alone, or in presence of liposomes (100 $\mu \mathrm{M})$. All these incubations were prepared in DTT-containing PBS medium. The conformation study of the oG37C peptide alone (Fig. 6 , black curve) allowed to identify an anti-parallel $\beta$-sheet conformation (bands at 1629 and $1683 \mathrm{~cm}^{-1}$ ) as already described for this oligomer $[24,47]$. It was established that these proportions depend on the oG37C treatment. In particular, it was previously shown that in presence of DTT, oG37C switched from a random conformation to an anti-parallel $\beta$-sheet organization [47], as observed here. However, these experiments were carried out after a very longer incubation time [47] in comparison with the present assay (15 days vs overnight here). A recent infrared nanospectroscopy study of the oG37C peptide with two membrane models allowed to highlight the pivotal role of cholesterol in the interactions with membrane. However, the FTIR spectrum analysis of the amide band I of oG37C bound to the membrane were not precisely carried out due to characteristic lipids band overlapping on the peptide amide I band [58].

In presence of $\mathrm{PC}_{622}$-based liposomes, no significant effect on the secondary structure of the oG37C peptide was observed (Fig. 6, green curve). In the presence of $\mathrm{PCG}_{226}$, the signal proportion in anti-parallel $\beta$-sheet decreased along with drastic increase of other secondary structure

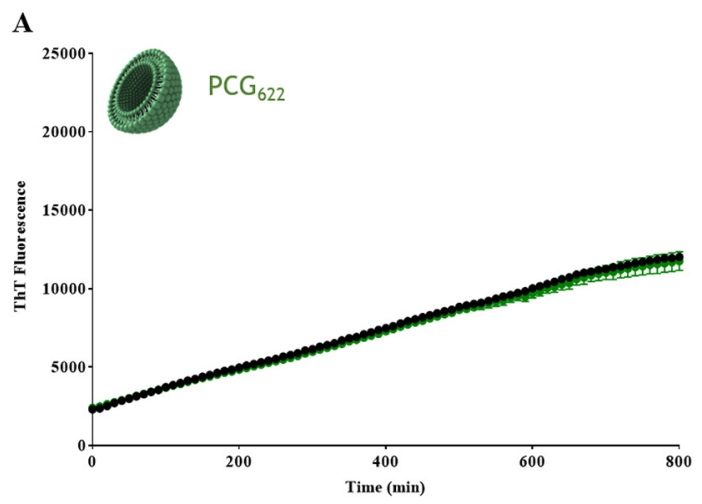

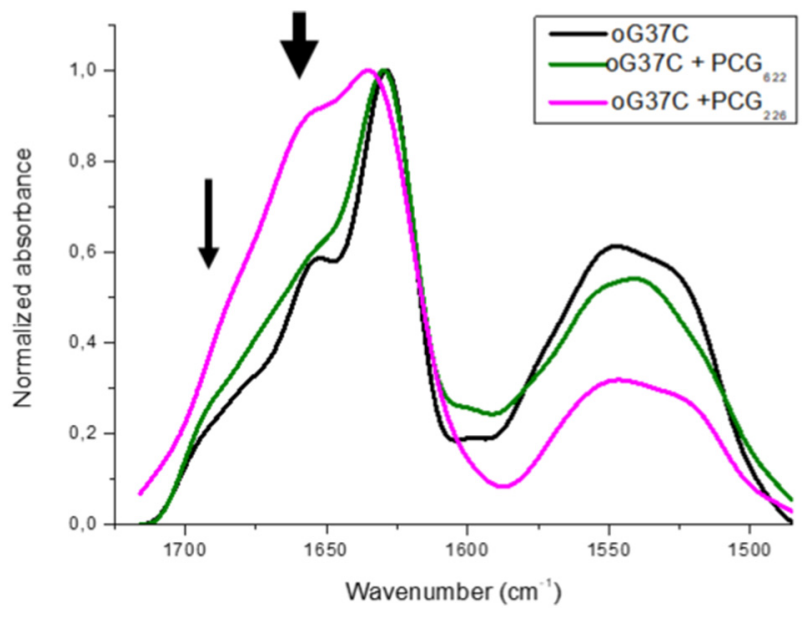

Fig. 6. ATR-FTIR spectra of amid band I and II absorbance of $A \beta_{1-42}$ peptide alone, with $\mathrm{PC}_{622}$ or $\mathrm{PC}_{226}$ formulations normalized to the $\beta$-sheet conformations band (1629 $\left.\mathrm{cm}^{-1}\right)$. The thin black arrow shows the anti-parallel $\beta$-sheet conformation at $1693 \mathrm{~cm}^{-1}$ of oG37C with or without lipid formulation. The bold black arrow shows importance of as $\alpha$-helical/random/ $\beta$-turn secondary structure of oG37C in presence of PCG $_{226}$-based LUVs.

elements as $\alpha$-helical/random/ $\beta$-turn. The global amide band I profile drew near the spectrum previously obtained in presence of cholesterol, sphingomyeline and phosphatidylcholine membrane [58].

Several studies have shown that $A B /$ membrane interactions lead to an increase in $\alpha$-helical conformation due to adsorption of the peptide on the membrane surface. Others have shown that this lipid interaction is accompanied by an increase of the $\beta$-sheet structuring linked to pore formation [44,63-65]. In our case, the main process would be the adsorption of the peptide on the membrane surface, and even insertion within the membrane. This anchorage was greater when the proportion of PG increased, leading to a detergent effect. Indeed, binding mechanisms were associated with toxicity as observed in leakage assay (Fig. 4).

OG37C insertion and detergent effect have been proved by Ewald, et al. to be dependent on the concomitant presence of GM1 and cholesterol [29]. It was also reported for a wild-type $A \beta$ peptide in the literature [13]. In the liposomal models we proposed, no GM1 was present. However, it could be possible that cholesterol facilitates the interaction of oG37C with membranes, and the concomitant presence of significant proportions (60\%) of negatively charged PG would also favor a detergent effect of the peptide.

\section{Discussion}

All the results showed that, in the presence of the selected lipids, the main effect observed was a delay in $A \beta_{1-42}$ fibrillation. The kinetic

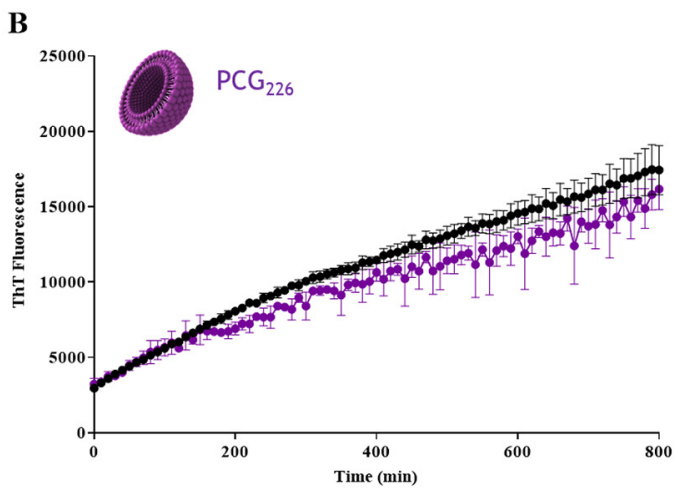

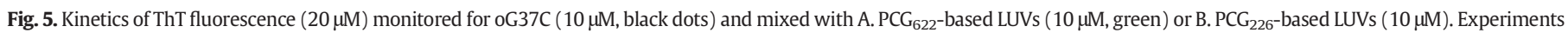
were prepared in a PBS-DTT based medium. The error bars represent the standard deviation of 3 samples. 
modifications seemed to take place mainly on the nucleation and elongation stages depending on the liposome concentration but also on their lipidic composition: the observed overall effect was the result of a partial effect produced by the different lipids at their own concentration, some having accelerating effects, others slowing down [10,36].

Thus, when the proportion of PG was increased, the toxic antiparallel $\beta$-sheet conformation appeared, which can be related to the presence of oligomers. Using the $\mathrm{oG} 37 \mathrm{C}$, interactions with membranes have been observed to be more important at higher PG proportion. It was previously reported that the $A \beta$ peptide would interact with GM1 clusters and that this interaction was facilitated by the presence of cholesterol [12]. The same type of phenomenon could occur with PCGbased LUVs formulated with a significant PG proportion. This interaction was reflected by an increase of the structural polymorphism (presence of $\alpha$-helix/random/ $\beta$-turns conformation) associated with destabilization of the liposome detectable by the liposome leakage assay.

Using ThT fluorescence measurements, electron microscopy and circular dichroism, the self-assembly of $A \beta_{1-42}$ has been shown to be decreased by anionic lipids [16]. Increasing the amount of negative charges by using $\mathrm{PCG}_{226}$ - instead of $\mathrm{PCG}_{622}$-based LUVs, we observed a longer delay with a prolongation of the nucleation and elongation phases. These observations may be attributed to a stabilizing effect of $A \beta$ peptide early species upon exposure to the liposomes. Indeed, as shown in the interaction model of the peptide with the membranes [66], the membranes would sequester the intermediary conformation species of the peptide, delaying its propensity to fibrillate.

The current paradigm concerning oligomers is that they can undergo two pathways: i) the on-pathway which corresponds to the formation of short-lived toxic species leading to amyloid fibers, and ii) the offpathway which implies structurally different monomers (formed upon exposure to external elements, for example membranes) proceeding to form higher molecular weight oligomers structurally different from their on-pathway counterparts [8,51]. Kinetic changes such as those we observed may indicate the presence of several aggregation pathways that could be borrowed by amyloid species, depending on the presence and composition of the liposomes used. In some studies, cholesterol was shown to promote $A \beta_{1-42}$ aggregation by acting on the nucleation phase [10]. However, other studies revealed that cholesterol containing vesicles can promote $A \beta$ fibrillation by hindering the nucleation process [67]. Kinetic changes such as those observed may indicate the presence of several aggregation pathways that could be borrowed by amyloid species depending on the presence and composition of the liposomes used.

The results obtained here showed that it is possible to finely characterize the $A \beta$ peptide aggregation process through three simple spectroscopic techniques permitting to reveal the aggregation kinetics, the peptide conformation and its membrane permeabilization property. This multiparametric assay enabled the characterization of peptide/ membrane interactions of two $A \beta$ peptide variants with two membrane models in various conditions. In particular, the PCG $_{226}$-based LUVs model permitted highlighting the interactions between membranes and the wild type or the oligomeric form of the peptide, in the same way than more complex membranes models previously described in the literature. Such an approach could be advantageously proposed as a simple multiparametric characterization to highlight peptide/membrane interactions (Fig. 7).

\section{Conclusion}

Our objectives were to characterize the effects of two liposomal formulations, mimicking the neuronal membranes, on the $A \beta$ aggregation

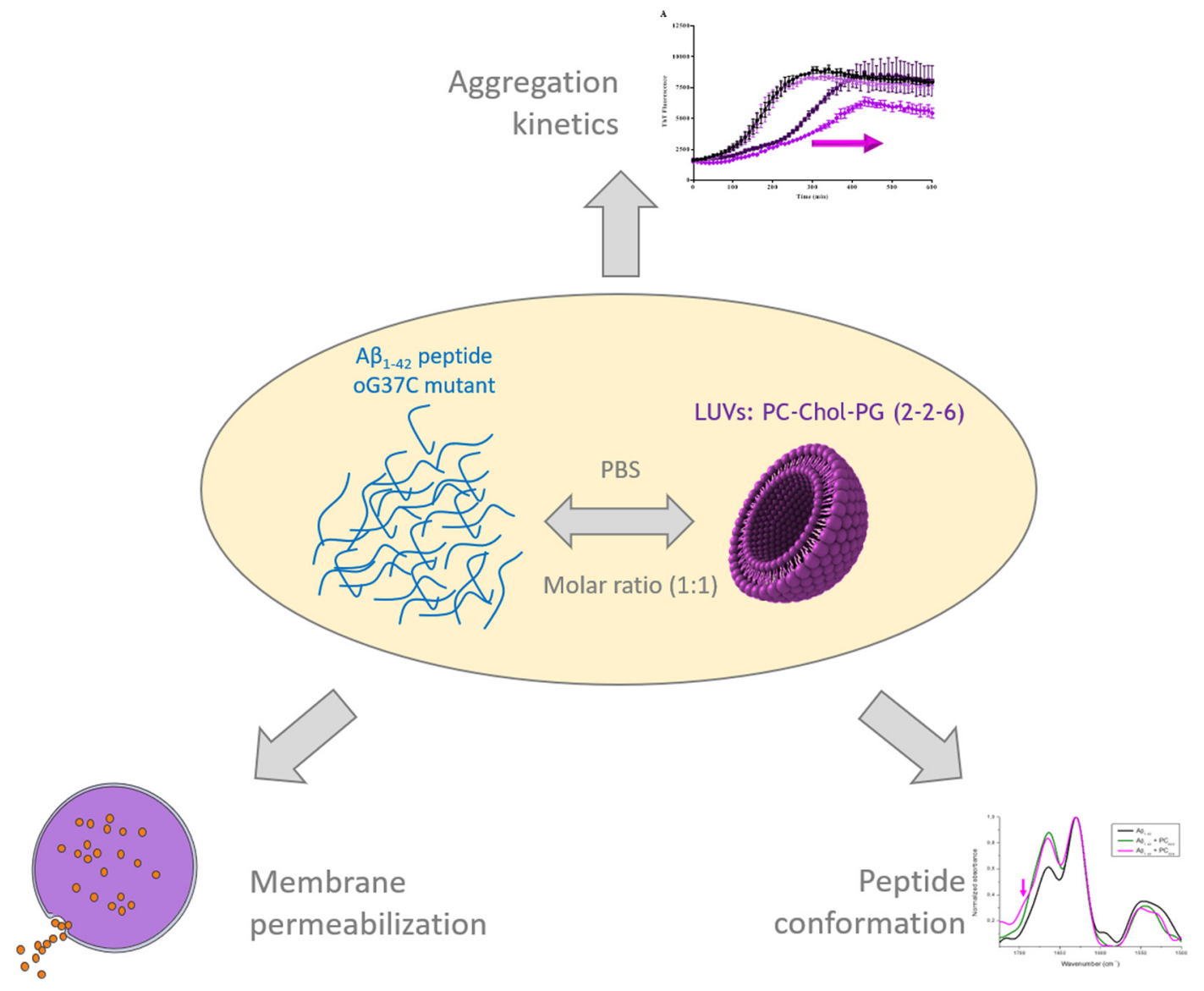

Fig. 7. Conditions and methods to highlight $A \beta$ peptide membrane interactions. 
pathway. Depending on the membrane composition and on the lipid: peptide ratio, the presence of lipids had mainly a slowing-down kinetic effect and a structural impact with a modification of the peptide conformation. Liposomes seemed to promote structural polymorphism of $A \beta_{1-}$ 42 , which led to a different oligomer aggregation pathway. The resulting species induced damages towards some membranes.

In order to propose a convenient peptide/membrane interaction model, $A \beta_{1-42}$ or oG37C peptides with $\mathrm{PC}_{226}$-based LUV used in a (1:1) lipid:peptide molar ratio, showed maximal changes on three parameters: membrane permeabilization, peptide conformation variation, and fibrillation kinetics. Therefore, results provided first methodologic bases to develop an original multiparametric assay to describe interactions of potential new $A \beta$ peptide aggregation modulators, peptide, and implying liposomes as biomimetic membranes.

\section{CRediT authorship contribution statement}

Conceptualization, W.S. and M.S. and A.M.F.; methodology, J.C., S.C. and C.C; software, J.C. and S. L.; formal analysis, SC, W.S, S.L.; resources, C.C.; writing-original draft preparation, W.S and A.M.F.; writingreview and editing, S. L., C.C., AMF and M.S.; supervision, M.S. and A.M. F; project administration, A.M.F.; funding acquisition, W.S., M.S. and A.M.F. All authors have read and agreed to the published version of the manuscript.

\section{Acknowledgments}

W. Smeralda was recipient of a doctoral fellowship from the French State (Research Ministry). This work was financially supported by the Region Normandie and the European Union via the European Regional Development Fund (FEDER).

\section{Appendix A. Supplementary data}

Supplementary data to this article can be found online at https://doi. org/10.1016/j.ijbiomac.2021.03.107.

\section{References}

[1] M.D. Benson, J.N. Buxbaum, D.S. Eisenberg, G. Merlini, M.J.M. Saraiva, Y. Sekijima, J.D. Sipe, P. Westermark, Amyloid nomenclature 2018: recommendations by the International Society of Amyloidosis (ISA) nomenclature committee, Amyloid 25 (2018) 215-219, https://doi.org/10.1080/13506129.2018.1549825.

[2] S.-Y. Ow, D.E. Dunstan, A brief overview of amyloids and Alzheimer's disease: amyloids and Alzheimer's disease, Protein Sci. 23 (2014) 1315-1331. doi:https://doi.org/ 10.1002/pro.2524.

[3] L. Dumery, F. Bourdel, Y. Soussan, A. Fialkowsky, S. Viale, P. Nicolas, M. ReboudRavaux, $\beta$-Amyloid protein aggregation: its implication in the physiopathology of Alzheimer's disease, Pathol. Biol. 49 (2001) 72-85, https://doi.org/10.1016/S03698114(00)00009-2.

[4] V.H. Finder, R. Glockshuber, Amyloid- $\beta$ aggregation, Neurodegener. Dis. 4 (2007) 13-27, https://doi.org/10.1159/000100355.

[5] G.K. Gouras, T.T. Olsson, O. Hansson, $\beta$-Amyloid peptides and amyloid plaques in Alzheimer's disease, Neurotherapeutics 12 (2015) 3-11, https://doi.org/10.1007/ s13311-014-0313-y.

[6] O.S. Makin, L.C. Serpell, Structures for amyloid fibrils: structures for amyloid fibrils, FEBS J. 272 (2005) 5950-5961, https://doi.org/10.1111/j.1742-4658.2005.05025.x.

[7] R. Nelson, M.R. Sawaya, M. Balbirnie, A.Ø. Madsen, C. Riekel, R. Grothe, D. Eisenberg, Structure of the cross- $\beta$ spine of amyloid-like fibrils, Nature 435 (2005) 773-778, https://doi.org/10.1038/nature03680.

[8] V. Rangachari, D.N. Dean, P. Rana, A. Vaidya, P. Ghosh, Cause and consequence of A $\beta$ - lipid interactions in Alzheimer disease pathogenesis, Biochim. Biophys. Acta BBA Biomembr. 1860 (2018) 1652-1662, https://doi.org/10.1016/j.bbamem.2018.03. 004.

[9] W. Gibson Wood, G.P. Eckert, U. Igbavboa, W.E. Müller, Amyloid beta-protein interactions with membranes and cholesterol: causes or casualties of Alzheimer's disease, Biochim. Biophys. Acta BBA - Biomembr. 1610 (2003) 281-290. doi:https:// doi.org/10.1016/S0005-2736(03)00025-7.

[10] J. Habchi, S. Chia, C. Galvagnion, T.C.T. Michaels, M.M.J. Bellaiche, F.S. Ruggeri, M. Sanguanini, I. Idini, J.R. Kumita, E. Sparr, S. Linse, C.M. Dobson, T.P.J. Knowles, M. Vendruscolo, Cholesterol catalyses A 342 aggregation through a heterogeneous nucleation pathway in the presence of lipid membranes, Nat. Chem. 10 (2018) 673-683, https://doi.org/10.1038/s41557-018-0031-x.
[11] T. Matsubara, H. Yasumori, K. Ito, T. Shimoaka, T. Hasegawa, T. Sato, Amyloid $\beta$ fibrils assembled on ganglioside-enriched membranes contain both parallel $\beta$-sheets and turns, J. Biol. Chem. (2018), jbc.RA118.002787, https://doi.org/10.1074/jbc.RA118. 002787.

[12] K. Matsuzaki, How do membranes initiate Alzheimer's disease? Formation of toxic amyloid fibrils by the amyloid $\beta$-protein on ganglioside clusters, Acc. Chem. Res. 47 (2014) 2397-2404, https://doi.org/10.1021/ar500127z.

[13] M.C. Nicastro, D. Spigolon, F. Librizzi, O. Moran, M.G. Ortore, D. Bulone, P.L.S. Biagio, R. Carrotta, Amyloid $\beta$-peptide insertion in liposomes containing GM1-cholesterol domains, Biophys. Chem. 208 (2016) 9-16. doi:https://doi.org/10.1016/j.bpc.2015. 07.010 .

[14] M. Vestergaard, T. Hamada, M. Morita, M. Takagi, Cholesterol, lipids, amyloid beta, and Alzheimers, Curr. Alzheimer Res. 7 (2010) 262-270, https://doi.org/10.2174/ 156720510791050821.

[15] P.K. Mandal, J.W. Pettegrew, Alzheimer's Disease: Soluble Oligomeric Ab(1-40) Peptide in Membrane Mimic Environment from Solution NMR and Circular Dichroism Studies, (n.d.) 6 .

[16] M.-A. Sani, J.D. Gehman, F. Separovic, Lipid matrix plays a role in Abeta fibril kinetics and morphology, FEBS Lett.. 585 (2011) 749-754. doi:https://doi.org/10.1016/j. febslet.2011.02.011.

[17] X. Yu, Q. Wang, Q. Pan, F. Zhou, J. Zheng, Molecular interactions of Alzheimer amyloid- $\beta$ oligomers with neutral and negatively charged lipid bilayers, Phys. Chem. Chem. Phys. 15 (2013) 8878-8889, https://doi.org/10.1039/C3CP44448A.

[18] E. Drolle, A. Negoda, K. Hammond, E. Pavlov, Z. Leonenko, Changes in lipid membranes may trigger amyloid toxicity in Alzheimer's disease, PLoS One 12 (2017), e0182194, https://doi.org/10.1371/journal.pone.0182194.

[19] K. Sasahara, K. Morigaki, K. Shinya, Effects of membrane interaction and aggregation of amyloid $\beta$-peptide on lipid mobility and membrane domain structure, Phys. Chem. Chem. Phys. 15 (2013) 8929, https://doi.org/10.1039/c3cp44517h.

[20] W. Smeralda, M. Since, S. Corvaisier, R. Legay, A.-S. Voisin-Chiret, A. Malzert-Freon, Microplate assay for lipophilicity determination using intrinsic fluorescence of drugs: application to a promising anticancer lead, pyridoclax, Eur. J. Pharm. Sci. 131 (2019) 75-83, https://doi.org/10.1016/j.ejps.2019.02.010.

[21] A.D. Bangham, M.M. Standish, J.C. Watkins, Diffusion of univalent ions across the lamellae of swollen phospholipids, J. Mol. Biol. 13 (1965) 238-IN27, https://doi.org/ 10.1016/S0022-2836(65)80093-6.

[22] R. Hein, C.B. Uzundal, A. Hennig, Simple and rapid quantification of phospholipids for supramolecular membrane transport assays, Org. Biomol. Chem. 14 (2016) 2182-2185, https://doi.org/10.1039/c5ob02480c.

[23] J.R. Jimah, P.H. Schlesinger, N.H. Tolia, Membrane lipid screen to identify molecular targets of biomolecules, Bio-Protoc 7 (2017)https://doi.org/10.21769/BioProtoc. 2427.

[24] H. Vignaud, C. Bobo, I. Lascu, K.M. Sörgjerd, T. Zako, M. Maeda, B. Salin, S. Lecomte, C. Cullin, A structure-toxicity study of Aß42 reveals a new anti-parallel aggregation pathway, PLoS One 8 (2013), e80262, https://doi.org/10.1371/journal.pone. 0080262.

[25] M.J. Hope, M.B. Bally, G. Webb, P.R. Cullis, Production of large unilamellar vesicles by a rapid extrusion procedure. Characterization of size distribution, trapped volume and ability to maintain a membrane potential, Biochim. Biophys. Acta BBA Biomembr. 812 (1985) 55-65. doi:https://doi.org/10.1016/0005-2736(85)90521-8.

[26] M. Lucio, J.L.F.C.L. and S. Reis, Drug-membrane interactions: significance for medicinal chemistry, Curr. Med. Chem. 17 (2010) 1795-1809. https://www.eurekaselect. com/60389/article (accessed September 24, 2020).

[27] Y. Sugiura, K. Ikeda, M. Nakano, High membrane curvature enhances binding, conformational changes, and fibrillation of amyloid- $\beta$ on lipid bilayer surfaces, Langmuir 31 (2015) 11549-11557, https://doi.org/10.1021/acs.langmuir.5b03332.

[28] M.S. Terakawa, Y. Lin, M. Kinoshita, S. Kanemura, D. Itoh, T. Sugiki, M. Okumura, A. Ramamoorthy, Y.-H. Lee, Impact of membrane curvature on amyloid aggregation, Biochim. Biophys. Acta BBA - Biomembr. 1860 (2018) 1741-1764, https://doi.org/ 10.1016/j.bbamem.2018.04.012.

[29] M. Ewald, S. Henry, E. Lambert, C. Feuillie, C. Bobo, C. Cullin, S. Lecomte, M. Molinari, High speed atomic force microscopy to investigate the interactions between toxic $A \beta_{1-42}$ peptides and model membranes in real time: impact of the membrane composition, Nanoscale 11 (2019) 7229-7238, https://doi.org/10.1039/C8NR08714H.

[30] S. Henry, H. Vignaud, C. Bobo, M. Decossas, O. Lambert, E. Harte, I.D. Alves, C. Cullin, S. Lecomte, Interaction of $A \beta_{1-42}$ amyloids with lipids promotes "off-pathway" oligomerization and membrane damage, Biomacromolecules 16 (2015) 944-950, https://doi.org/10.1021/bm501837w.

[31] R.O. Calderon, B. Attema, G.H. DeVries, Lipid composition of neuronal cell bodies and neurites from cultured dorsal root ganglia, J. Neurochem. 64 (1995) 424-429, https://doi.org/10.1046/j.1471-4159.1995.64010424.x.

[32] M. Biancalana, S. Koide, Molecular mechanism of Thioflavin-T binding to amyloid fibrils, Biochim. Biophys. Acta BBA - Proteins Proteomics. 1804 (2010) 1405-1412. doi:https://doi.org/10.1016/j.bbapap.2010.04.001.

[33] J. Habchi, S. Chia, R. Limbocker, B. Mannini, M. Ahn, M. Perni, O. Hansson, P. Arosio J.R. Kumita, P.K. Challa, S.I.A. Cohen, S. Linse, C.M. Dobson, T.P.J. Knowles, M. Vendruscolo, Systematic development of small molecules to inhibit specific microscopic steps of Aß42 aggregation in Alzheimer's disease, Proc. Natl. Acad. Sci. 114 (2017) E200-E208, https://doi.org/10.1073/pnas.1615613114.

[34] D. Bhowmik, A.K. Das, S. Maiti, Rapid, cell-free assay for membrane-active forms of amyloid-B, Langmuir 31 (2015) 4049-4053, https://doi.org/10.1021/la502679t.

[35] B. Chandra, D. Bhowmik, B.K. Maity, K.R. Mote, D. Dhara, R. Venkatramani, S. Maiti, P.K. Madhu, Major reaction coordinates linking transient amyloid- $\beta$ oligomers to fibrils measured at atomic level, Biophys. J. 113 (2017) 805-816, https://doi.org/10. 1016/j.bpj.2017.06.068. 
[36] M. Sanguanini, K.N. Baumann, S. Preet, S. Chia, J. Habchi, T.P.J. Knowles, M. Vendruscolo, Complexity in lipid membrane composition induces resilience to Aß42 aggregation, ACS Chem. Neurosci. 11 (2020) 1347-1352, https://doi.org/10. 1021/acschemneuro.0c00101.

[37] D.J. Lindberg, E. Wesén, J. Björkeroth, S. Rocha, E.K. Esbjörner, Lipid membranes catalyse the fibril formation of the amyloid- $\beta$ (1-42) peptide through lipid-fibril interactions that reinforce secondary pathways, Biochim. Biophys. Acta BBA - Biomembr. 1859 (2017) 1921-1929. doi:https://doi.org/10.1016/j.bbamem.2017.05.012.

[38] R. Sarroukh, E. Goormaghtigh, J.-M. Ruysschaert, V. Raussens, ATR-FTIR: a "rejuvenated" tool to investigate amyloid proteins, Biochim. Biophys. Acta BBA - Biomembr. 1828 (2013) 2328-2338. doi:https://doi.org/10.1016/j.bbamem.2013.04.012.

[39] E. Cerf, R. Sarroukh, S. Tamamizu-Kato, L. Breydo, S. Derclaye, Y.F. Dufrêne, V. Narayanaswami, E. Goormaghtigh, J.-M. Ruysschaert, V. Raussens, Antiparallel $\beta-$ sheet: a signature structure of the oligomeric amyloid $\beta$-peptide, Biochem. J. 421 (2009) 415-423, https://doi.org/10.1042/BJ20090379.

[40] K. Berthelot, F. Immel, J. Géan, S. Lecomte, R. Oda, B. Kauffmann, C. Cullin, Driving amyloid toxicity in a yeast model by structural changes: a molecular approach, FASEB J. 23 (7) (2009) 2254-2263https://www.fasebj.org/doi/abs/10.1096/fj.08125724.

[41] J.-M. Ruysschaert, V. Raussens, ATR-FTIR analysis of amyloid proteins, in: B.L. Nilsson, T.M. Doran (Eds.), Pept. Self-Assem. Methods Protoc, Springer, New York, NY 2018, pp. 69-81, https://doi.org/10.1007/978-1-4939-7811-3_3.

[42] D. Bhowmik, K.R. Mote, C.M. MacLaughlin, N. Biswas, B. Chandra, J.K. Basu, G.C. Walker, P.K. Madhu, S. Maiti, Cell-membrane-mimicking lipid-coated nanoparticles confer Raman enhancement to membrane proteins and reveal membrane-attached amyloid- $\beta$ conformation, ACS Nano 9 (2015) 9070-9077, https://doi.org/10.1021/ acsnano.5b03175.

[43] T. Hoshino, Md.I. Mahmood, K. Mori, K. Matsuzaki, Binding and aggregation mechanism of amyloid $\beta$-peptides onto the GM1 ganglioside-containing lipid membrane, J. Phys. Chem. B 117 (2013) 8085-8094, https://doi.org/10.1021/jp4029062.

[44] K. Matsuzaki, Physicochemical interactions of amyloid $\beta$-peptide with lipid bilayers, Biochim. Biophys. Acta BBA - Biomembr. 1768 (2007) 1935-1942, https://doi.org/ 10.1016/j.bbamem.2007.02.009.

[45] E. Hellstrand, E. Sparr, S. Linse, Retardation of A $\beta$ fibril formation by phospholipid vesicles depends on membrane phase behavior, Biophys. J. 98 (2010) 2206-2214, https://doi.org/10.1016/j.bpj.2010.01.063.

[46] M. Ahmed, J. Davis, D. Aucoin, T. Sato, S. Ahuja, S. Aimoto, J.I. Elliott, W.E. Van Nostrand, S.O. Smith, Structural conversion of neurotoxic amyloid- $\beta$ 1-42 oligomers to fibrils, Nat. Struct. Mol. Biol. 17 (2010) 561-567, https://doi.org/10.1038/nsmb. 1799.

[47] C. Bobo, S. Chaignepain, S. Henry, H. Vignaud, A. Améadan, C. Marchal, E. Prado, J. Doutch, J.-M. Schmitter, C. Nardin, S. Lecomte, C. Cullin, Synthetic toxic A $1-42$ oligomers can assemble in different morphologies, Biochim. Biophys. Acta BBA Gen. Subj. 1861 (2017) 1168-1176, https://doi.org/10.1016/j.bbagen.2017.03.001.

[48] P. Cizas, R. Budvytyte, R. Morkuniene, R. Moldovan, M. Broccio, M. Lösche, G. Niaura, G. Valincius, V. Borutaite, Size-dependent neurotoxicity of $\beta$-amyloid oligomers, Arch. Biochem. Biophys. 496 (2010) 84-92, https://doi.org/10.1016/j.abb.2010.02. 001.

[49] E.N. Cline, M.A. Bicca, K.L. Viola, W.L. Klein, The amyloid- $\beta$ oligomer hypothesis: beginning of the third decade, J. Alzheimers Dis. 64 (2018) S567-S610, https://doi.org/ 10.3233/JAD-179941.

[50] R. Kayed, C.A. Lasagna-Reeves, Molecular mechanisms of amyloid oligomers toxicity, J. Alzheimers Dis. 33 (2012) S67-S78, https://doi.org/10.3233/JAD-2012-129001.

[51] S.J.C. Lee, E. Nam, H.J. Lee, M.G. Savelieff, M.H. Lim, Towards an understanding of amyloid- $\beta$ oligomers: characterization, toxicity mechanisms, and inhibitors, Chem. Soc. Rev. 46 (2017) 310-323, https://doi.org/10.1039/C6CS00731G.
[52] U. Sengupta, A.N. Nilson, R. Kayed, The role of amyloid- $\beta$ oligomers in toxicity, propagation, and immunotherapy, EBioMedicine 6 (2016) 42-49, https://doi.org/10. 1016/j.ebiom.2016.03.035.

[53] B. Chandra, S. Halder, J. Adler, A. Korn, D. Huster, S. Maiti, Emerging structural details of transient amyloid- $\beta$ oligomers suggest designs for effective small molecule modulators, Chem. Phys. Lett. 675 (2017) 51-55, https://doi.org/10.1016/j.cplett.2017. 02.070 .

[54] L. Breydo, V.N. Uversky, Structural, morphological, and functional diversity of amyloid oligomers, FEBS Lett.. 589 (2015) 2640-2648. doi:https://doi.org/10.1016/j. febslet.2015.07.013.

[55] M. Fa, I.J. Orozco, Y.I. Francis, F. Saeed, Y. Gong, O. Arancio, Preparation of oligomeric $\beta$-amyloid1-42 and induction of synaptic plasticity impairment on hippocampal slices, JoVE J. Vis. Exp. (2010) e1884, https://doi.org/10.3791/1884.

[56] W.B. Stine, L. Jungbauer, C. Yu, M.J. LaDu, Preparing synthetic A $\beta$ in different aggregation states, in: E.D. Roberson (Ed.), Alzheimers Dis. Front. Dement. Methods Protoc, Humana Press, Totowa, NJ 2011, pp. 13-32, https://doi.org/10.1007/978-160761-744-0_2.

[57] S. Bonhommeau, D. Talaga, J. Hunel, C. Cullin, S. Lecomte, Tip-enhanced Raman spectroscopy to distinguish toxic oligomers from $A \beta_{1-42}$ fibrils at the nanometer scale, Angew. Chem. Int. Ed. 56 (2017) 1771-1774, https://doi.org/10.1002/anie. 201610399.

[58] S. Henry, N.B. Bercu, C. Bobo, C. Cullin, M. Molinari, S. Lecomte, Interaction of A $1-42$ peptide or their variant with model membrane of different composition probed by infrared nanospectroscopy, Nanoscale 10 (2018) 936-940, https://doi. org/10.1039/C7NR07489A.

[59] S. Nag, B. Sarkar, A. Bandyopadhyay, B. Sahoo, V.K.A. Sreenivasan, M. Kombrabail, C. Muralidharan, S. Maiti, Nature of the amyloid- $\beta$ monomer and the monomeroligomer equilibrium, J. Biol. Chem. 286 (2011) 13827-13833, https://doi.org/10. 1074/jbc.M110.199885.

[60] D.A. Delgado, K. Doherty, Q. Cheng, H. Kim, D. Xu, H. Dong, C. Grewer, W. Qiang, Distinct membrane disruption pathways are induced by 40 -residue $\beta$-amyloid peptides, J. Biol. Chem. 291 (2016) 12233-12244, https://doi.org/10.1074/jbc.M116. 720656.

[61] S. Amin, G.V. Barnett, J.A. Pathak, C.J. Roberts, P.S. Sarangapani, Protein aggregation, particle formation, characterization \& rheology, Curr. Opin. Colloid Interface Sci. 19 (2014) 438-449, https://doi.org/10.1016/j.cocis.2014.10.002.

[62] L.R. Arriaga, I. López-Montero, F. Monroy, G. Orts-Gil, B. Farago, T. Hellweg, Stiffening effect of cholesterol on disordered lipid phases: a combined neutron spin Echo + dynamic light scattering analysis of the bending elasticity of large unilamellar vesicles, Biophys. J. 96 (2009) 3629-3637, https://doi.org/10.1016/j.bpj.2009.01.045.

[63] R. Lal, H. Lin, A.P. Quist, Amyloid beta ion channel: 3D structure and relevance to amyloid channel paradigm, Biochim. Biophys. Acta BBA - Biomembr. 1768 (2007) 1966-1975. doi:https://doi.org/10.1016/j.bbamem.2007.04.021.

[64] A. Quist, I. Doudevski, H. Lin, R. Azimova, D. Ng, B. Frangione, B. Kagan, J. Ghiso, R. Lal, Amyloid ion channels: a common structural link for protein-misfolding disease, Proc. Natl. Acad. Sci. 102 (2005) 10427-10432, https://doi.org/10.1073/pnas. 0502066102.

[65] Y. Xu, J. Shen, X. Luo, W. Zhu, K. Chen, J. Ma, H. Jiang, Conformational transition of amyloid -peptide, Proc. Natl. Acad. Sci. 102 (2005) 5403-5407, https://doi.org/10. 1073/pnas.0501218102.

[66] Z. Niu, Z. Zhang, W. Zhao, J. Yang, Interactions between amyloid $\beta$ peptide and lipid membranes, Biochim. Biophys. Acta BBA - Biomembr. 1860 (2018) 1663-1669, https://doi.org/10.1016/j.bbamem.2018.04.004.

[67] H.T.T. Phan, N. Shimokawa, N. Sharma, M. Takagi, M.C. Vestergaard, Strikingly different effects of cholesterol and 7-ketocholesterol on lipid bilayer-mediated aggregation of amyloid beta (1-42), Biochem. Biophys. Rep. 14 (2018) 98-103, https:// doi.org/10.1016/j.bbrep.2018.04.007. 